EXTENDED REPORT

\title{
HLA-DMA*0103 and HLA-DMB*0104 alleles as novel prognostic factors in rheumatoid arthritis
}

\author{
J Morel, F Roch-Bras, N Molinari, J Sany, J F Eliaou, B Combe
}

Ann Rheum Dis 2004;63:1581-1586. doi: 10.1136/ard.2003.012294

See end of article for authors' affiliations

........

Correspondence to: Dr J Morel, Department of Immuno-Rheumatology, Hospital Lapeyronie 34295, Montpellier cedex 5, France; i-morel@ chu-montpellier.fr

Accepted 17 January 2004

\begin{abstract}
Objective: To evaluate HLA-DM alleles as markers for disease severity in rheumatoid arthritis (RA).
Methods: Two distinct cohorts of patients with RA were oligotyped for HLA-DB1 and HLA-DM genes using PCR amplified genomic DNA with sequence specific oligonucleotide probes. Cohort 1 comprised 199 unselected patients with RA (mean (SD) age 45.5 (13.5) years; disease duration 11.9(8.8) years), whose disease severity was assessed using Larsen score on hand and foot radiographs. Cohort 2 comprised 95 patients with severe RA and 70 patients with benign RA according to the Larsen method.

Results: In cohort 1, after stratification according to DRB1 genotypes, patients positive for HLA-DMA*0103 and negative for HLA-DRB $1{ }^{*} 04$ tended to have greater articular damage on hands and wrists $(p=0.07$ by Mann-Whitney $U$ test) and reached statistical significance for the Larsen score per year $(p=0.05)$. This association between HLA-DMA*0103 and articular damage was especially observed in patients with HLA$D R B 1 * 01$. Similarly, HLA-DMB*0104 positive patients had higher Larsen score on hands and wrists $(p=0.02)$. This association was even stronger in $D R B 1{ }^{*} 04$ positive patients $(p=0.005)$. In cohort $2, H L A-$ $D M A^{*} 0103$ was associated with severe RA in patients negative for HLA-DRB1 ${ }^{*} 04(O D=5.4 ; p=0.014)$. HLA-DMB*0104 allele frequency tended to be higher in patients with severe RA but without reaching significance.

Conclusion: This is the first study evaluating the role of HLA-DM genes in the severity of RA. Our results suggest that HLA-DMA*0103 and HLA-DMB*0104 alleles may represent new genetic markers of RA severity. The HLA-DMA*0103 allele tends to be associated with patients with RA negative for DRB $1{ }^{*} 04$ and could predict a more severe form of disease especially in HLA-DRB ${ }^{*} 01$ positive patients. The HLA$D M B^{*} 0104$ allele could have an additive effect in HLA-DRB $1^{*} 04$ patients. Combined determination of HLA-DM and HLA-DRB1 alleles could facilitate identification of patients likely to have a poor disease course.
\end{abstract}

$\mathrm{T}$ he pattern of rheumatoid arthritis (RA) progression may vary from benign to severe with shorter survival. In about $10 \%$ of patients with RA, severe joint damage occurs with important functional disability within 2 years of disease evolution. ${ }^{1}$ It has been extensively demonstrated that early therapeutic intervention with antirheumatic drugs considerably improves the prognosis of RA. ${ }^{2}$ This highlights the importance of determining the course of the disease so that therapies with the best risk/benefit ratio can be used. Therefore, it would be very useful to be able to predict the course of RA in any particular patient. Poor outcome in patients with RA is associated with severity of initial activity, extra-articular manifestations, and severe degree of physical disability at onset. ${ }^{3}$ Erythrocyte sedimentation rate, C reactive protein, presence of high levels of rheumatoid factor and anticitrullinated peptide/protein antibodies at onset, early occurrence of bony erosions, and presence of HLA-DRBl genes conferring susceptibility to RA are also important prognostic markers. ${ }^{4-6}$ The major histocompatibility complex (MHC) genes encode the $\alpha$ and $\beta$ chain of the heterodimer HLA-DR molecule that presents antigenic peptide to the T lymphocyte receptor (TCR). ${ }^{7}$ In white populations, RA is essentially associated with the HLA-DRBI*0l, $\mathrm{DRBI}^{*} 10$, and $\mathrm{DRBl}^{*} 04$ genes. ${ }^{8}$ The presence of one these susceptibility alleles influences the course and severity of RA because patients with these alleles have extra-articular features and higher frequencies of joint damage. ${ }^{10}$ There is a dose dependent effect of HLA-DRBI genes; the presence of a second RA susceptibility allele increases the risk of developing a destructive disease or extra-articular manifestations. ${ }^{11}$ Thus, patients with $\mathrm{DRBI}^{*} 04$, particularly homozygotes, have a higher risk of developing a severe disease than patients with only one $\mathrm{DRBI}^{*} 0 \mathrm{l}$ gene or $\mathrm{DRBI}^{*} \mathrm{X}$. Because HLA-DRBI susceptibility alleles are not found in $20-25 \%$ of patients with RA, other genetic factors have been evaluated. HLA-DM, another component of the $\mathrm{MHC}$, is of particular interest because of its biological interaction with the HLA-DR molecule. In the endosomal compartments, HLA-DM molecules catalyse the exchange and the selection of ligands for MHC class II molecules. ${ }^{12}{ }^{13}$ HLA-DMA and DMB genes have limited nucleotide polymorphisms in the third exon. To date, four DMA alleles and six DMB alleles have been described. ${ }^{14} 15$

We showed in a previous study that the HLA-DMA*0103 and $\mathrm{DMB}^{*} 0104$ alleles were significantly increased in RA. ${ }^{16}$ In this study, we evaluated them as potential prognosis markers of RA. Radiographic characteristics of patients with RA belonging to two distinct cohorts were analysed, and correlations between these parameters and HLA-DM and HLADRBl alleles were assessed. HLA-DMA 0103 is associated with severe RA in patients positive for HLA-DRBI*01. Patients with both HLA-DMB 0104 and DRBI ${ }^{*} 04$ have more severe disease. These results support the idea of HLA$\mathrm{DMA}^{*} 0103$ and $\mathrm{DMB}^{*} 0104$ as novel prognostic markers in RA.

Abbreviations: DMARD, disease modifying antirheumatic drug; MHC, major histocompatibility complex; RA, rheumatoid arthritis; RF, rhematoid factor; TCR, T lymphocyte receptor 
Table 1 Distribution of HLA-DRB1 genotypes in patients with RA (cohortl and cohort 2), and random and matched controls

\begin{tabular}{|c|c|c|c|c|c|c|c|c|}
\hline \multirow[b]{2}{*}{ Genes } & \multicolumn{2}{|c|}{ RA cohort 1} & \multicolumn{2}{|c|}{ RA cohort 2} & \multicolumn{2}{|c|}{ Random controls } & \multicolumn{2}{|c|}{ Matched controls } \\
\hline & $\bar{n}$ & GF (\%) & $\bar{n}$ & GF (\%) & $\bar{n}$ & GF $(\%)$ & $n$ & GF (\%) \\
\hline $\mathrm{DRB} 1{ }^{*} 04 \dagger$ & 100 & 50.3 & 80 & 25.6 & 34 & 22.8 & 96 & 44 \\
\hline *04/04 & 20 & 10.1 & 15 & 9 & 4 & 2.7 & 15 & 6.9 \\
\hline *04/01 & 14 & 7 & 12 & 7.2 & 10 & 6.7 & 16 & 7.3 \\
\hline${ }^{*} 04 / X$ & 66 & 33.2 & 53 & 32.1 & 20 & 13.4 & 66 & 30.3 \\
\hline DRB ${ }^{*} 01 \neq$ & 51 & 25.6 & 47 & 28.5 & 51 & 34.2 & 58 & 26.6 \\
\hline${ }^{*} 01 / 01$ & 6 & 3 & 5 & 3 & 4 & 2.7 & 6 & 2.8 \\
\hline${ }^{*} 01 / 04$ & 14 & 7 & 12 & 7.2 & 10 & 6.7 & 16 & 7.3 \\
\hline${ }^{*} 01 / \mathrm{X}$ & 31 & 15.9 & 30 & 18.2 & 37 & 24.8 & 38 & 17.4 \\
\hline $\mathrm{DRB} 1{ }^{*} \mathrm{X} / \mathrm{X}$ & 62 & 31.1 & 50 & 30.3 & 74 & 49.7 & 78 & 35.6 \\
\hline
\end{tabular}

\section{MATERIALS AND METHODS \\ Patients}

HLA-DM genes distribution was examined in two distinct cohorts of patients with RA. Cohort 1 was composed of 199 patients who participated in a previous study to determine whether HLA-DMA and DMB genes contribute to the genetic susceptibility to RA. ${ }^{16}$ Patient records were analysed for clinical, biological and radiological informations. Cohort 2 was composed of 165 patients, divided according to Larsen's grade damage into those with severe $(n=95)$ and those with benign $(n=70)$ RA. ${ }^{3}$ Two unrelated control populations were used in this study. Healthy volunteer bone marrow donors served as control groups. One group consisted of 147 individuals who were randomly selected and typed for HLA-DRB 1 and HLA-DM. Another group of 218 individuals was closely matched for the HLA-DRBl genotype with the RA patient groups. Patients fulfilled $\geqslant 4$ of the American College of Rheumatology 1987 revised criteria for the classification of RA. All patients and controls were of white origin and from the Montpellier area.

\section{Methods}

Genomic DNA was extracted from peripheral blood mononuclear cells according to the classic salting out procedure. HLA-DRBI alleles were typed as previously described. Polymorphisms of the HLA-DMA and DMB genes were determined following PCR amplification of genomic DNA using two specific pairs of primers. Hybridisation of the PCR

\begin{tabular}{|c|c|c|}
\hline Gene & $n$ & GF (\%) \\
\hline DRB 1*0401/0401 & 4 & 2 \\
\hline DRB $1 * 0401 / 0404$ & 9 & 4.5 \\
\hline DRB $1 * 0401 / 0405$ & 2 & 1 \\
\hline DRB $1 * 0404 / 0404$ & 1 & 0.5 \\
\hline DRB $1 * 0405 / 0405$ & 2 & 0.5 \\
\hline DRB $1 * 0408 / 0408$ & 2 & 0.5 \\
\hline DRB $1 * 0101 / 0401$ & 10 & 0.5 \\
\hline DRB $1 * 0101 / 0404$ & 1 & 0.5 \\
\hline DRB $1 * 0101 / 0405$ & 1 & 0.5 \\
\hline DRB $1 * 0102 / 0401$ & 1 & 0.5 \\
\hline DRB $1 * 0102 / 0404$ & 1 & 0.5 \\
\hline DRB 1*0401/X & 41 & 20.6 \\
\hline DRB 1*0404/X & 19 & 9.5 \\
\hline$D R B 1 * 0405 / X$ & 6 & 3 \\
\hline DRB $1 * 0101 / 0101$ & 6 & 3 \\
\hline DRB $1 * 0101 / X$ & 28 & 14 \\
\hline $\mathrm{DRB} 1 * 0102 / \mathrm{X}$ & 3 & 1.5 \\
\hline
\end{tabular}

products with the respective DMA and DMB panel of sequence specific oligonucleotide probes was performed using a nonradioactive direct dot blot procedure. HLA$\mathrm{DMA}^{*} 0101$ to 0104 and HLA-DMB*0101 to 0106 were oligotyped. All patients had been HLA-DRBI* and HLA-DM genotyped.

\section{Assessment of radiographic disease progression}

All films were evaluated by two different trained rheumatologists who were blinded to clinical data and typing results. The films were assessed according to Larsen method. This method evaluates 32 joints: 10 metacarpophalangeal joints, 8 proximal interphalangeal joints, 2 interphalangeal joints of the thumbs, 2 wrists, 8 metatarsophalangeal joints II-V, and the interphalangeal joints of the great toes. Grading of joints is based on standard radiographic films and varies between 0 and 5. For the wrist, the score was multiplied by 5. Scores were added for the hands and feet separately. The total score per patient can range from 0 to 150 for the hands and 0 to 50 for the feet. To examine a correlation between HLA-DM alleles and radiological progression, a separate analysis of $x$ rays of hands and feet was made because these were not available for all patients. Because radiological progression varies with disease duration, Larsen score was divided by the number of years of disease duration (Larsen score/year).

For cohort 2, the severity of the disease was essentially evaluated on structural damage assessed by Larsen's grade of damage classification calculated on hand and foot $x$ rays. A Larsen's grade $\geqslant 4$ on hands and feet defined a severe RA whereas a Larsen's grade $<2$ defined a benign RA, as previously described. ${ }^{3}$

\section{Statistical analyses}

Statistical analyses were performed using the program S.plus (Department of Epidemiology and Sstatistics of University of Medicine, Montpellier, France). Odds ratios were calculated by the method of Woolf, with Haldane's modification for small numbers. For quantitative values, the significance of difference was determined by the Mann-Whitney $U$ test, with significance set at 0.05 .

\section{RESULTS}

\section{Patient characteristics}

A total of 199 unselected patients were included in cohort 1 (157F and 42M, mean (SD) age 45.5 (13.5) years (range 2-84), mean (SD) disease duration (8.8) 11.9 years); 40 patients $(20.1 \%)$ had rheumatoid nodules, 28 patients (14.1\%) had Raynaud's syndrome, and 73 (36.8\%) had Sjogren's syndrome. Other extra-articular features were seen in 19 patients: 10 skin vasculitis, 2 pericarditis, 3 with association of skin vasculitis and pericarditis, 1 amyloidosis, 
Table 3 Allele and genotype frequencies of HLA-DMA in patients with RA, and matched and random controls

\begin{tabular}{|c|c|c|c|c|c|c|c|c|c|}
\hline \multirow[b]{3}{*}{ DMA } & \multicolumn{3}{|c|}{ DRB $1 * 01 / 01$ and $01 / \mathrm{X}$} & \multicolumn{3}{|c|}{ DRB $1 * 04 / 04$ and $04 / X$} & \multicolumn{3}{|l|}{$\mathrm{DRB} 1^{*} \mathrm{X} / \mathrm{X}$} \\
\hline & \multicolumn{3}{|l|}{$n(\%$ AF) } & \multicolumn{3}{|l|}{$\mathrm{n}(\%$ AF) } & \multicolumn{3}{|l|}{$n(\%$ AF) } \\
\hline & $\begin{array}{l}\text { RA cohort } 1 \\
(n=37)\end{array}$ & $\begin{array}{l}\text { Matched } \\
(n=44)\end{array}$ & $\begin{array}{l}\text { Random } \\
(n=41)\end{array}$ & $\begin{array}{l}\text { RA cohort } 1 \\
(n=100)\end{array}$ & $\begin{array}{l}\text { Matched } \\
(\mathrm{n}=81)\end{array}$ & $\begin{array}{l}\text { Random } \\
(n=24)\end{array}$ & $\begin{array}{l}\text { RA cohort } 1 \\
(n=62)\end{array}$ & $\begin{array}{l}\text { Matched } \\
(n=78)\end{array}$ & $\begin{array}{l}\text { Random } \\
(\mathrm{n}=74)\end{array}$ \\
\hline${ }^{*} 0101$ & $57(77)$ & $74(84)$ & $72(87.8)$ & $173(86.5)$ & $149(92)$ & $42(87.5)$ & $100(80.6)$ & $139(89.1)$ & 131 (88.5) \\
\hline *0102 & $6(8.1)$ & $13(14.8)$ & 10 (11.4) & $19(9.5)$ & $9(5.6)$ & $4(8.3)$ & 17 (13.7) & $16(10.2)$ & 16 (10.8) \\
\hline *0103 & 10 (13.5) & $1(1.1)$ & 0 & $8(8)$ & $4(2.4)$ & $1(2)$ & $6(4.8)$ & $1(0.7)$ & $1(0.7)$ \\
\hline *0104 & $1(1.4)$ & 0 & 0 & 0 & 0 & $1(2)$ & $1(0.8)$ & 0 & 0 \\
\hline $\begin{array}{l}* 0101 / \\
0101\end{array}$ & $20(54)$ & $74(84)$ & $72(87.8)$ & $76(76)$ & $68(84)$ & $18(75)$ & $39(62.9)$ & 61 (78.2) & 57 (77) \\
\hline $\begin{array}{l}{ }^{*} 0101 / 1 \\
0102\end{array}$ & $6(16.2)$ & $13(14.8)$ & $10(11.4)$ & $17(17)$ & $9(11.1)$ & $4(16.4)$ & $15(24.1)$ & $16(20.5)$ & $16(21.6)$ \\
\hline $\begin{array}{l}{ }^{*} 0101 / 1 \\
0103\end{array}$ & $10(27)$ & $1(1.1)$ & 0 & $4(4)$ & $4(4.9)$ & $1(4.2)$ & $6(9.7)$ & $1(1.3)$ & $1(1.4)$ \\
\hline $\begin{array}{l}{ }^{*} 0101 / 1 \\
0104\end{array}$ & $1(2.7)$ & 0 & 0 & 0 & 0 & 0 & $1(1.6)$ & 0 & 0 \\
\hline $\begin{array}{l}{ }^{*} 0102 / \\
0102\end{array}$ & 0 & 0 & 0 & 0 & 0 & 0 & $1(1.6)$ & 0 & 0 \\
\hline $\begin{array}{l}* 0102 / \\
0103\end{array}$ & 0 & 0 & 0 & $2(2)$ & 0 & 0 & 0 & 0 & 0 \\
\hline $\begin{array}{l}* 0103 / \\
0103\end{array}$ & 0 & 0 & 0 & $1(1)$ & 0 & 0 & 0 & & \\
\hline $\begin{array}{l}* 0103 / \\
0104\end{array}$ & 0 & 0 & 0 & 0 & 0 & $1(4.2)$ & 0 & 0 & 0 \\
\hline
\end{tabular}

and 1 Felty's syndrome. There were 115 patients (57.8\%) positive for rheumatoid factor and $45(22.7 \%)$ for ANA. Patients with RA had been treated with 3.88 (2.22) disease modifying antirheumatic drugs (DMARDs) and 96 (47.7\%) had had surgery. HLA-DRBl and HLA-DM genotype and allele frequencies are presented in tables $1-4$. Of the patients oligotyped for HLA-DMA and DMB, 137 in cohort 1 (68.8\%) and 115 in cohort $2(72.5 \%)$ respectively, carried at least one susceptibility allele to RA: HLA-DRB 1*0401, 0404, 0405, 0408, 0101 , or 0102. Alleles other than these susceptibility alleles were classified as HLA-DRB1*X. Radiograms of hands were available for 192 patients, with a mean (SD) Larsen's score of 54.6 (42.8); for feet, $173 x$ ray films were read, Larsen's score 19.9 (18.1).

In cohort 2, two subgroups were created according to the degree of radiographic severity of the disease. The severe RA group comprised 95 patients with Larsen's score $\geqslant 4$; disease duration was 8.1 (5.8) years. The benign RA group comprised 70 patients with Larsen's score $<2$; disease duration in this group was 8.4 (3.5) years. HLA-DRB1* genotypes and HLADMA genotype and allele frequencies in these two groups are

\begin{tabular}{|c|c|c|}
\hline \multirow[b]{2}{*}{ DMB } & \multicolumn{2}{|l|}{ n (\% GF) } \\
\hline & $\begin{array}{l}\text { RA cohort } 1 \\
(\mathrm{n}=91)\end{array}$ & $\begin{array}{l}\text { Matched } \\
(n=81)\end{array}$ \\
\hline${ }^{*} 0101 / 0101$ & $33(40.7)$ & $45(55.6)$ \\
\hline${ }^{*} 0101 / 0102$ & $2(2.5)$ & $5(6.2)$ \\
\hline${ }^{*} 0101 / 0103$ & $21(25.9)$ & $21(25.9)$ \\
\hline${ }^{*} 0101 / 0104$ & $20(21.9)$ & $4(4.9)$ \\
\hline${ }^{*} 0102 / 0103$ & $4(4.9)$ & $2(2.5)$ \\
\hline${ }^{*} 0102 / 0104$ & $2(2.5)$ & $1(1.2)$ \\
\hline${ }^{*} 0103 / 0103$ & $4(4.9)$ & $3(3.7)$ \\
\hline *0103/0104 & $5(6.2)$ & 0 \\
\hline${ }^{*} 0101$ & $109(59.9)$ & $120(74)$ \\
\hline *0102 & $8(4.4)$ & $8(4.9)$ \\
\hline${ }^{*} 0103$ & $38(20.8)$ & $29(17.9)$ \\
\hline *0104 & 27 (14.8) & 5 (3) \\
\hline
\end{tabular}

shown in tables 5 and 6. RA susceptibility allele HLA$\mathrm{DRBI}^{*} 04$ but not DRBI ${ }^{*} 01$ was significantly associated with severe RA $(p<0.05)$, whereas patients without any of the RA susceptibility allele had benign RA $(p<0.05)$.

\section{HLA-DMA*0103 phenotype correlates with greater radiographic damage}

In cohort 1, 198 patients with RA were typed for HLA-DMA. Distribution of HLA-DMA alleles was not different for sex, age at disease onset, extra-articular features, rheumatoid factor (RF), anti-nuclear antibodies (ANA), or medical treatments. Orthopaedic surgery was performed on $65 \%$ of patients carrying HLA-DMA*0103. Therefore the presence of HLA-DMA*0103 tended to be associated with higher levels of surgical procedures $(p=0.08)$. To control for the influence of HLA-DRBI ${ }^{*} 04$ on RA severity, we combined analysis of HLA-DM and DRBI allele distribution. Again, age at onset of RA, extra-articular features, RF, ANA, and treatment received were not different between HLA-DMA*0103/non-DRB1 ${ }^{*} 04$ and non-DMA*0103/non-DRB1*04 haplotypes. However, in non-DRBI ${ }^{*} 04$ patients, the presence of DMA*0103 tended to be associated with greater articular damage to hands and wrists (table 7 ). This association reached statistical significance for the Larsen score/year $(p=0.05)$. A similar trend was observed for feet, but was not significant $(p=0.11)$.

In cohort 2, the relation of HLA-DMA*0103 with articular damage was particularly evident in the groups of patients

Table 5 Distribution of HLA-DRB1 genotypes in patients with severe and benign RA (cohort 2)

\begin{tabular}{lllll}
\hline DRB 1 & $\begin{array}{l}\text { Severe RA } \\
\text { (n=95) }\end{array}$ & $\begin{array}{l}\text { Benign RA } \\
\text { ( } \mathbf{n = 7 0 )}\end{array}$ & OR (95\% Cl) & $\mathbf{p}$ \\
\hline${ }^{*} 04 / 04$ & 10 & 5 & $9(1.1$ to 73.7$)$ & 0.014 \\
${ }^{*} 04 / 01$ & 11 & 1 & $2(1.08$ to 4.29$)$ & 0.03 \\
${ }^{*} 04 / \mathrm{X}$ & 37 & 16 & & $\mathrm{NS}$ \\
${ }^{*} 01 / 01$ & 4 & 1 & & $\mathrm{NS}$ \\
${ }^{*} 01 / \mathrm{X}$ & 20 & 10 & & \\
${ }^{*} \mathrm{X} / \mathrm{X}$ & 13 & 37 & $0.14(0.06$ to 0.29$)$ & $<0.0001$ \\
\hline
\end{tabular}

$X$ is any HLA-DRB 1 gene other than HLA-DRB $1{ }^{*} 04$ and 01 alleles. $\chi^{2}$ test was used for analysis. 
Table 6 Distribution of the HLA-DMA alleles and genotypes in patients with severe and benign RA (cohort 2) and matched controls, according to the HLA-DRB1 genotypes

\begin{tabular}{|c|c|c|c|c|c|c|c|c|}
\hline \multirow[b]{3}{*}{ DMA } & \multicolumn{2}{|c|}{ DRB $1 * 01 / 01$ et $01 / \mathrm{X}$} & \multicolumn{2}{|c|}{ DRB $1 * 04 / 04$ et $04 / X$} & \multicolumn{2}{|c|}{ DRB $1 * 04 / 01$} & \multicolumn{2}{|l|}{ DRB $1^{*} \mathrm{X} / \mathrm{X}$} \\
\hline & \multicolumn{2}{|l|}{$n(\%$ AF) } & \multicolumn{2}{|l|}{$n(\%$ AF) } & \multicolumn{2}{|l|}{$n(\%$ AF) } & \multicolumn{2}{|l|}{$n$ (\% AF) } \\
\hline & $\begin{array}{l}\text { Severe } \\
(n=24)\end{array}$ & $\begin{array}{l}\text { Benign } \\
(\mathrm{n}=11)\end{array}$ & $\begin{array}{l}\text { Severe } \\
(\mathrm{n}=47)\end{array}$ & $\begin{array}{l}\text { Benign } \\
(n=21)\end{array}$ & $\begin{array}{l}\text { Severe } \\
(\mathrm{n}=11)\end{array}$ & $\begin{array}{l}\text { Benign } \\
(n=1)\end{array}$ & $\begin{array}{l}\text { Severe } \\
(n=13)\end{array}$ & $\begin{array}{l}\text { Benign } \\
(\mathrm{n}=37)\end{array}$ \\
\hline${ }^{*} 0101$ & $39(81.3)$ & $19(86.4)$ & $85(90.4)$ & 35 (83.3) & $18(81.8)$ & 0 & $21(80.8)$ & $64(86.4)$ \\
\hline${ }^{*} 0102$ & $1(2)$ & $2(9)$ & $5(5.3)$ & $6(14.3)$ & $2(9)$ & $1(50)$ & $2(7.7)$ & $7(9.5)$ \\
\hline${ }^{*} 0103$ & $8(16.7)$ & $1(4.5)$ & 1 (1) & $1(2.4)$ & $2(9)$ & $1(50)$ & $2(7.7)$ & $2(2.7)$ \\
\hline *0104 & 0 & 0 & $3(3.2)$ & 0 & 0 & 0 & $1(3.8)$ & $1(1.4)$ \\
\hline *0101/0101 & $15(62.5)$ & $8(72.7)$ & $39(83)$ & $15(71.4)$ & $7(63.6)$ & 0 & $9(69.2)$ & $29(78.4)$ \\
\hline$* 0101 / 0102$ & $1(4.2)$ & $2(18.2)$ & $3(6.4)$ & 5 (23.8) & 2 (18.2) & 0 & $1(7.7)$ & $3(8.1)$ \\
\hline${ }^{*} 0101 / 0103$ & 8 (33.3) & 1 (9) & $1(2.1)$ & 0 & 2 (18.2) & 0 & $1(7.7)$ & $2(5.4)$ \\
\hline$* 0101 / 0104$ & 0 & 0 & $3(6.3)$ & 0 & 0 & 0 & $1(7.7)$ & $1(2.7)$ \\
\hline${ }^{*} 0102 / 0102$ & 0 & 0 & $1(2.1)$ & 0 & 0 & 0 & 0 & $2(5.4)$ \\
\hline$* 0102 / 0103$ & 0 & 0 & 0 & $1(4.8)$ & 0 & $1(100)$ & $1(7.7)$ & 0 \\
\hline
\end{tabular}

listed as severe and benign RA. As shown in table 8, HLA$\mathrm{DMA}^{*} 0103$ frequency in non-DRB1*04 patients was much higher in severe RA $(p=0.014)$. In the benign RA group, HLA-DMA*0103 frequency was similar to that observed in an HLA matched control group. In $\mathrm{DRBI}^{*} 01$ positive patients, the presence of HLA-DMA*0103 was associated with severe RA $(p=0.037)$.

\section{HLA-DMB*0104 phenotype correlates with greater radiographic damage}

In cohort 2, 160 patients were typed for HLA-DMB. HLA$\mathrm{DMB}^{*} 0104$ positive patients with RA received more DMARDs than $\mathrm{DMB}^{*} 0104$ negative patients $(4.74$ (2.23) v 3.74 (2.19); $\mathrm{p}=0.015)$. They also had a significantly higher Larsen score on hand and wrist $x$ rays $(p=0.02)$. Very similar results were observed for patients with the HLA-DMB ${ }^{*} 0104 / \mathrm{DRBI}^{*} 04$ and HLA-DMB ${ }^{*} 0104 /$ non-DRB $1^{*} 04$ haplotypes (table 9). These patients were treated with more DMARDs and had more articular damage on hands and wrists. There was the same trend on foot $x$ rays, but it did not reach statistical significance. In cohort 2, we observed the same tendency; HLA-DMB*0104 allele frequency was higher in severe RA compared with benign RA, but it was not statistically significant (data not shown).

\section{DISCUSSION}

In this retrospective study, we examined the relation between known markers of severity and HLA-DM alleles in two different cohorts of patients with RA. We particularly focused on HLA-DMA*0103 and HLA-DMB*0104, because we had previously reported that these alleles were associated with RA susceptibility. ${ }^{16}$ patients with RA carrying HLA-DMA*0103 and HLA-DRBI*01 had greater articular damage, and the HLA-DMA*0103 positive patients tended to have more surgical procedures. HLA-DMB*0104 was associated with structural damage in patients positive for HLA-DRBI ${ }^{*} 04$. Sex ratio, age at disease onset, extra-articular features, and biological features in our population of patients with RA were very similar to those observed in other studies, ${ }^{17}{ }^{18}$ and $70 \%$ of our patients carry at least one HLA-DRBl RA susceptibility allele (HLA-DRBI*0401, *0404, ${ }^{*} 0405$, or ${ }^{*} 0408$, or DRBI ${ }^{*} 0101$ or $\left.{ }^{*} 0102\right)$. The high prevalence of the HLADRBI*01 and DRBI*04 genotypes has been extensively reported. ${ }^{17} 1920$ The HLA-DM phenotypic frequencies in our population of patients with RA are similar to those observed in healthy controls except for HLA-DMA*0103 and $\mathrm{DMB}^{*} 0104$ as previously reported. ${ }^{16}$ Phenotypic frequencies of these alleles in patients with RA were significantly higher. For HLA-DMA*0103, this frequency was $13 \%$ v $3 \%$ in controls and for HLA-DMB*0104, 17\% $\vee 7 \%$. In the literature, there are conflicting results regarding the association between HLADM alleles and RA. Half of these studies reported a difference in the distribution of HLA-DM genes between patients and controls. Toussirot et al found the same association with HLA$\mathrm{DMA}^{*} 0103$, but not with $\mathrm{DMB}^{*} 0104 .{ }^{21}$ In two other French studies, authors reported an association with HLA-DMB*0101 in western France and HLA-DMA*0101 in Corsica. ${ }^{22}{ }^{23}$ Five studies did not find any association. ${ }^{24-28}$ These discrepancies may result from ethnic disparities, as two of these studies concerned Asian patients. The distribution of HLA-DRBl alleles has also been described according to racial origin. However, ethnic variation is probably not the only explanation, because the three other studies comprised white populations. Geographical factors may account for variations in distribution of HLA-DM alleles, and size samples may also explain the absence of statistical differences between groups. For example, Singal and Ye reported very similar phenotype frequencies for HLA-DMA alleles but in significantly smaller samples: HLA-DMA*0103 frequencies were $14.29 \%$ in 54 patients with RA and $3.70 \%$ in 56 controls. In the two cohorts

Table 7 Articular damage on hands and feet in patients with HLA-DMA*0103 phenotype in cohort 1

\begin{tabular}{|c|c|c|c|c|c|c|c|}
\hline Allele & $\mathbf{n}$ & $\begin{array}{l}\text { Larsen score: } \\
\text { hands and } \\
\text { wrists }\end{array}$ & $\mathbf{p}$ & $\begin{array}{l}\text { Larsen score/ } \\
\text { year: hands } \\
\text { and wrists }\end{array}$ & $\mathbf{p}$ & $\begin{array}{l}\text { Larsen score: } \\
\text { feet }\end{array}$ & $\mathbf{p}$ \\
\hline $\mathrm{DMA}^{*} 0103+$ & 25 & $62.5(42.2)$ & & ND & & $19.7(14.1)$ & \\
\hline DMA*0103 - & 173 & $53.3(41.9)$ & 0.27 & ND & & $17.7(16)$ & 0.58 \\
\hline \multicolumn{8}{|l|}{ DRB ${ }^{*} 04$ negative } \\
\hline $\mathrm{DMA}^{*} 0103+$ & 9 & $63.4(38.8)$ & & $8.5(7.5)$ & & $19.8(13.2)$ & \\
\hline $\mathrm{DMA}^{*} 0103-$ & 90 & $42.8(40.5)$ & 0.07 & $5.8(6.4)$ & 0.05 & $15.9(14.1)$ & 0.11 \\
\hline
\end{tabular}


Table 8 Articular damage to hands and feet in patients with RA with HLA-DMA*0103 phenotype in cohort 2

\begin{tabular}{|c|c|c|c|c|c|}
\hline Allele & $\begin{array}{l}\text { Matched } \\
\text { controls } \\
(n=218)\end{array}$ & $\begin{array}{l}\text { Severe } \\
\text { RA } \\
(n=95)\end{array}$ & $\begin{array}{l}\text { Benign } \\
\text { RA } \\
(n=70)\end{array}$ & OR $(95 \%$ Cl) & $\mathbf{p}$ \\
\hline \multicolumn{6}{|l|}{ Non DRB 1*04 } \\
\hline $\mathrm{DMA}^{*} 0103+$ & 2 & 10 & 3 & & \\
\hline DMA*0103 - & 120 & 28 & 45 & 5.4 (1.4 to 21.2$)$ & 0.014 \\
\hline \multicolumn{6}{|c|}{$\mathrm{DRB} 1 * 01 / 01$ and $01 / \mathrm{X}$} \\
\hline $\mathrm{DMA}^{*} 0103+$ & 1 & 8 & 1 & & \\
\hline $\mathrm{DMA}^{*} 0103-$ & 43 & 16 & 11 & $11.8(0.62$ to 225$)$ & 0.037 \\
\hline
\end{tabular}

$\mathrm{OR}$, odds ratio; $\mathrm{Cl}$, confidence interval. Disease severity was assessed using Larsen score on hand and foot radiographs. Severe RA corresponds to a Larsen score $>3$; benign RA corresponds to a Larsen score $<2$. $\chi^{2}$ test was used for analyses.

of patients with RA, HLA-DMA*0103 was associated with radiographic severity in non-HLA-DRBI*04 patients. Linkage disequilibrium between HLA-DMA 0103 and HLA-DRBI*01 may explain this association, as Reviron et al, in a population geographically close to ours, found that differences in DMA phenotype frequencies between patients and controls were secondary to linkage disequilibrium. ${ }^{25}$ However, we did not find any linkage disequilibrium using the $\Delta$ values for nonrandom assortment of alleles in control subjects. Moreover, for HLA-DMA*0103, this association could not be explained by a linkage disequilibrium because this allele was also increased in patients negative for the RA susceptibility $\mathrm{DRBI}^{*} 04$ alleles. The HLA-DMA*0103 allele was not correlated with known markers of severity in RA including sex, age at disease onset, extraarticular features, erythrocyte sedimentation rate, $\mathrm{C}$ reactive protein, and rheumatoid factor (RF).

Patients with RA with HLA-DMA*0103 allele did not require more DMARDs but tended to undergo more surgical procedures. This association between HLA-DMA*0103 and bone destruction was more evident when considering the

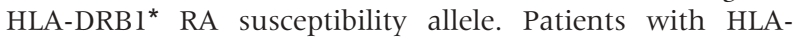
$\mathrm{DMA}^{*} 0103$ and non HLA-DRBI*04 susceptibility alleles had higher Larsen score and Larsen score/year calculated on hand $x$ ray. The role of HLA-DMA*0103 in the severity of RA became statistically significant when we compared allele distribution in groups of patients with severe and benign RA. Indeed, patients with severe RA (Larsen score $\geqslant 4$ ) had a higher frequency of HLA-DMA*0103/non DRBI*04 phenotype compared with those with benign RA $(p=0.014)$ and in matched controls $(p<0.0001)$. This independence between $\mathrm{DMA}^{*} 0103$ and $\mathrm{DRB} \mathrm{I}^{*} 04$ suggests that HLA-DMA*0103 could be associated with the progression and severity of RA in patients without $\mathrm{DRBI}^{*} 04$ alleles. Moreover, in cohort 2, the presence of HLA-DMA 0103 associated with HLA-DRBI ${ }^{*} 01$ was higher in patients with severe RA than in those with benign RA and in matched controls, Thus, HLA-DMA*0103 may represent an additional predictive factor of structural damage in patients with RA and HLA-DRBI*01 alleles.

HLA-DMB ${ }^{*} 0104$ may also be involved in the severity of RA. Patients carrying HLA-DMB*0104 took more DMARDs and had a higher Larsen score on hand $x$ ray. This was also true for HLA-DRBI ${ }^{*}$ 04. HLA-DMB ${ }^{*} 0104$ may represent an additional factor of severity in patients with $\mathrm{DRBI}^{*} 04$ or DRX alleles.

This is the first study evaluating the role of HLA-DM genes in the severity of RA. These results support the idea that HLA$\mathrm{DMA}^{*} 0103$ and HLA-DMB${ }^{*} 0104$ are associated with the progression of structural damage in RA. Such correlation between genes and the degree of disease severity has only been described previously for HLA-DRBI* ${ }^{*}$ genes. ${ }^{31}$ The HLADRBI*04 alleles correlate with more severe forms of disease, whereas HLA-DRB $1^{*} 01$ associated with milder RA. It may be useful in these HLA-DRB ${ }^{*} 01$ positive patients to determine the presence or not of HLA-DMA*0103, as a combination of these two alleles is more often distributed in severe RA. The combined presence of these two alleles in addition to other prognostic factors could help to identify patients with poor prognosis. This result has to be confirmed by prospective studies. The clinical benefit of HLA-DMB*0104 typing seems to be less evident because of its reliance on HLA-DRI ${ }^{*} 04$. However, because of this close relation between these two alleles, it might be of interest to study the functional consequences of HLA-DM and HLA-DR interaction on antigen presentation in patients with RA carrying both HLA-DRB1 ${ }^{*} 04$ and HLA-DMB*0104.

In conclusion, our study brings evidence that the HLA$\mathrm{DMA}^{*} 0103$ and $\mathrm{DMB}^{*} 0104$ alleles could be new genetic markers of RA severity. HLA-DMA*0103 could predict a more severe form of disease in patients with no HLA-DRBI*04 susceptibility alleles, especially in $\mathrm{HLA}^{\mathrm{DRB}}{ }^{*} 01$ positive

\section{Key messages}

- HLA-DMA*0103 and HLA-DMB*0104 may represent new predictive markers of severity in RA.

- Patients carrying the $\mathrm{HLA}-\mathrm{DRB} 1^{*} 01$ gene along with HLA-DMA*0103 or HLA-DRB 1*01, and HLA$D M B^{*} 0104$ have greater structural damage.

Table 9 Articular damage on hands and feet in patients with HLA-DMB*0104 phenotype

\begin{tabular}{|c|c|c|c|c|c|}
\hline Allele & $\mathbf{n}$ & $\begin{array}{l}\text { Larsen score: } \\
\text { hands and } \\
\text { wrists }\end{array}$ & $\mathbf{p}$ & $\begin{array}{l}\text { Larsen score: } \\
\text { feet }\end{array}$ & $\mathbf{p}$ \\
\hline $\mathrm{DMB}^{*} 0104+$ & 27 & $70.7(46.4)$ & & $22.7(16.3)$ & \\
\hline $\mathrm{DMB}^{*} 0104-$ & 133 & $51.9(41.8)$ & 0.02 & 19.5 (18.7) & 0.15 \\
\hline \multicolumn{6}{|l|}{ DRB $1{ }^{*} 04$ positive } \\
\hline $\mathrm{DMB}^{*} 0104+$ & 17 & 89.8 (42.2) & & $26.2(16.5)$ & \\
\hline $\mathrm{DMB}^{*} 0104$ - & 72 & $55.2(40.1)$ & $<0.005$ & $19.3(15.1)$ & 0.14 \\
\hline
\end{tabular}


patients. HLA-DMB*0104 could have an additive effect in HLA-DRBI*04 patients. Combined determination of HLA-DM and HLA-DRB 1 alleles could facilitate identification of patients likely to have a poor disease course, particularly joint destruction. This genetic analysis may help to select patients who could benefit of the more efficacious drug therapies.

\section{ACKNOWLEDGMENTS}

This work was supported by grants from Société Française de Rhumatologie.

\section{Authors' affiliations}

J Morel, F Roch-Bras, J Sany, B Combe, Department of Immuno-

Rheumatology, Hospital Lapeyronie, Montpellier, France

N Molinari, Department of Epidemiology and Public Health, Nîmes,

France

J F Eliaou, Department of Immunology, Hospital Saint-Eloi, Montpellier, France

\section{REFERENCES}

1 Masi AT. Articular patterns in the early course of rheumatoid arthritis. Am J Med 1983;75:16-26.

2 van der Heijde DM, van Riel PL, Nuver-Zwart IH, Gribnau FW, van de Putte LB. Effects of hydroxychloroquine and sulphasalazine on progression of joint damage in rheumatoid arthritis. Lancet 1989;1:1036-8.

3 Combe B, Eliaou JF, Daures JP, Meyer O, Clot J, Sany J. Prognostic factors in rheumatoid arthritis. Comparative study of two subsets of patients according to severity of articular damage. Br J Rheumatol 1995:34:529-34.

4 van der Heijde DM, van Riel PL, van Leeuwen MA, van't Hof MA, van Rijswijk MH, van de Putte LB. Prognostic factors for radiographic damage and physical disability in early rheumatoid arthritis. A prospective follow-up study of 147 patients. Br J Rheumatol 1992;31:519-35.

5 Emery P, Salmon M, Bradley H, Wordsworth P, Tunn E, Bacon PA, et al. Genetically determined factors as predictors of radiological change in patients with early symmetrical arthritis. BMJ 1992;305:1387-9.

6 Meyer O, Labarre C, Dougados M, Goupille P, Cantagrel A, Dubois A, et al. Anticitrullinated protein/peptide antibody assays in early rheumatoid arthritis for predicting five year radiographic damage. Ann Rheum Dis 2003;62:120-6.

7 Spies T, Sorrentino R, Boss JM, Okada K, Strominger JL. Structural organization of the DR subregion of the human major histocompatibility complex. Proc Natl Acad Sci USA 1985:82:5165-9.

8 Nepom GT, Byers P, Seyfried C, Healey LA, Wilske KR, Stage D, et al. HLA genes associated with rheumatoid arthritis. Identification of susceptibility alleles using specific oligonucleotide probes. Arthritis Rheum 1989;32:15-21
9 Weyand CM, Xie C, Goronzy JJ. Homozygosity for the HLA-DRB 1 allele selects for extraarticular manifestations in rheumatoid arthritis. J Clin Invest 1992;89:2033-9.

10 Wagner U, Kaltenhauser S, Sauer H, Arnold S, Seidel W, Hantzschel H, Kalden JR, Wassmuth R. HLA markers and prediction of clinical course and outcome in rheumatoid arthritis. Arthritis Rheum 1997;40:341-51.

11 Weyand CM, McCarthy TG, Goronzy JJ. Correlation between disease phenotype and genetic heterogeneity in rheumatoid arthritis. $J$ Clin Invest 1995:95:2120-6.

12 Pathak SS, Lich JD, Blum JS. Cutting edge: editing of recycling class II: peptide complexes by HLA-DM. J Immunol 2001;167:632-5.

13 Kropshofer H, Hammerling GJ, Vogt AB. How HLA-DM edits the MHC class II peptide repertoire: survival of the fittest? Immunol Today 1997;18:77-82.

14 Bodmer JG, Marsh SG, Albert ED, Bodmer WF, Bontrop RE, Charron D, et al. Nomenclature for factors of the HLA System, 1996. Hum Immunol 1997; 53:98-128

15 McTernan CL, Mijovic CH, Cockram CS, Barnett AH. The nucleotide sequence of a new DMB allele, DMB*0106. Tissue Antigens 2000;55:470-2.

16 Pinet V, Combe B, Avinens O, Caillat-Zucman S, Sany J, Clot J, et al. Polymorphism of the HLA-DMA and DMB genes in rheumatoid arthritis. Arthritis Rheum 1997;40:854-8.

17 Alarcon GS. Epidemiology of rheumatoid arthritis. Rheum Dis Clin North Am 1995;21:589-604.

18 Symmons DP, Barrett EM, Bankhead CR, Scott DG, Silman AJ. The incidence of rheumatoid arthritis in the United Kingdom: results from the Norfolk Arthritis Register. Br J Rheumatol 1994;33:735-9.

19 Mason JH, Anderson JJ, Meenan RF. A model of health status for rheumatoid arthritis. A factor analysis of the Arthritis Impact Measurement Scales. Arthritis Rheum 1988;31:714-20.

20 Meenan RF, Mason JH, Anderson JJ, Guccione AA, Kazis LE. AIMS2. The content and properties of a revised and expanded Arthritis Impact Measurement Scales Health Status Questionnaire. Arthritis Rheum 1992;35:1-10.

21 Toussirot E, Sauvageot C, Chabod J, Ferrand C, Tiberghien P, Wendling D. The association of HLA-DM genes with rheumatoid arthritis in Eastern France. Hum Immunol 2000;61:303-8.

22 Perdriger A, Guggenbuhl P, Chales G, Yaouang J, Quelvennec E Bonnard MN, et al. Positive association of the HLA DMB1*0101-0101 genotype with rheumatoid arthritis. Rheumatology 1999;38:448-52.

23 Cucchi-Mouillot P, Lai S, Carcassi C, Sorba P, Stuart-Simoni M, Amoros JP, et al. Implication of HLA-DMA alleles in corsican IDDM. Dis Markers 1998; 14:135-41.

24 Singal DP, Ye M. HLA-DM polymorphisms in patients with rheumatoid arthritis. J Rheumatol 1998;25:1295-8.

25 Reviron D Tezenas du Montcel S, Foutrier C, Guis S, Benazet JF, Auquier P et al. HLA DRB 1, DMA, and DMB gene polymorphisms in rheumatoid arthritis. Hum Immunol 1999;60:245-9.

26 Yen JH, Chen CJ, Tsai WC, Tsai JJ, Chang JG, Liu HW. HLA-DMA and DMB genotyping in patients with rheumatoid arthritis. J Rheumatol 1997:24:442-4.

27 Takeuchi $\mathrm{F}$, Nabeta $\mathrm{H}$, Kuwata $\mathrm{S}$, Tanimoto $\mathrm{K}$, Ito $\mathrm{K}$. Association of DMA and DMB with RA in Japanese. Clin Exp Rheumatol 1997;15:189-92.

28 Moxley G, Han J. HLA DMA and DMB show no association with rheumatoid arthritis in US Caucasians. Eur J Immunogenet 2001 ;28:539-43. 